\title{
Inhalable Microparticles Embedding Calcium Phosphate Nanoparticles for Heart Targeting: The Formulation Experimental Design
}

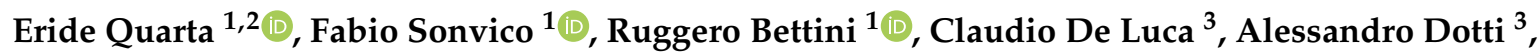

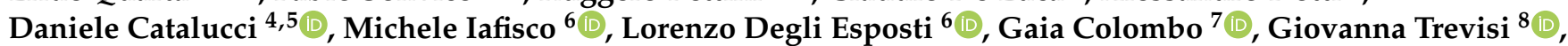 \\ Dimitrios M. Rekkas ${ }^{9}$, Alessandra Rossi ${ }^{1}{ }^{\mathbb{D}}$, Tin Wui Wong ${ }^{10}$, Francesca Buttini ${ }^{1, *}$ and Paolo Colombo ${ }^{1,2, *}$
}

Citation: Quarta, E.; Sonvico, F.; Bettini, R.; De Luca, C.; Dotti, A.; Catalucci, D.; Iafisco, M.; Degli Esposti, L.; Colombo, G.; Trevisi, G. et al. Inhalable Microparticles Embedding Calcium Phosphate Nanoparticles for Heart Targeting: The Formulation Experimental Design. Pharmaceutics 2021, 13, 1825 https://doi.org/10.3390/ pharmaceutics 13111825

Academic Editor: Jesus Perez-Gil

Received: 24 September 2021

Accepted: 23 October 2021

Published: 1 November 202

Publisher's Note: MDPI stays neutral with regard to jurisdictional claims in published maps and institutional affiliations.

Copyright: (C) 2021 by the authors Licensee MDPI, Basel, Switzerland This article is an open access article distributed under the terms and conditions of the Creative Commons Attribution (CC BY) license (https:// creativecommons.org/licenses/by/ $4.0 /)$.
1 Food and Drug Department, University of Parma, Parco Area delle Scienze 27/A, 43124 Parma, Italy; eride.quarta@studenti.unipr.it (E.Q.); fabio.sonvico@unipr.it (F.S.); ruggero.bettini@unipr.it (R.B.); alessandra.rossi@unipr.it (A.R.)

2 PlumeStars Srl., c/o Food \& Drug Department, Parco Area delle Scienze 27A, 43124 Parma, Italy

3 Fin-Ceramica Faenza SPA, Via Granarolo 177/3, 48018 Faenza, Italy; cdeluca@finceramica.it (C.D.L.); alessandro.dotti@finceramica.it (A.D.)

4 IRCCS Humanitas Research Hospital, 20089 Rozzano, Italy; daniele.catalucci@cnr.it

5 Institute of Genetic and Biomedical Research (IRGB)-UOS Milan, National Research Council (CNR), 20138 Milan, Italy

6 Institute of Science and Technology for Ceramics (ISTEC), National Research Council (CNR), Via Granarolo 64, 48018 Faenza, Italy; michele.iafisco@istec.cnr.it (M.I.); lorenzo.degliesposti@istec.cnr.it (L.D.E.)

7 Department of Life Sciences and Biotechnology, University of Ferrara, Via Fossato di Mortara 17/19, 44121 Ferrara, Italy; clmgai@unife.it

8 Institute of Materials for Electronics and Magnetism (IMEM), National Research Council (CNR), Parco Area delle Scienze 37/A, 43124 Parma, Italy; giovanna.trevisi@imem.cnr.it

9 Department of Pharmacy, National and Kapodistrian University of Athens, 15784 Zografou, Athens, Greece; rekkas@pharm.uoa.gr

10 Non-Destructive Biomedical and Pharmaceutical Research Centre, Smart Manufacturing Research Institute, Universiti Teknologi MARA, Puncak Alam 42300, Selangor, Malaysia; wongtinwui@uitm.edu.my

* Correspondence: francesca.buttini@unipr.it (F.B.); paolo.colombo@plumestars.com or paolo.colombo@unipr.it (P.C.); Tel.: +39-0521-906008 (F.B.); +39-0521-905086 (P.C.)

\begin{abstract}
Inhalation of Calcium Phosphate nanoparticles (CaPs) has recently unmasked the potential of this nanomedicine for a respiratory lung-to-heart drug delivery targeting the myocardial cells. In this work, we investigated the development of a novel highly respirable dry powder embedding crystalline CaPs. Mannitol was selected as water soluble matrix excipient for constructing respirable dry microparticles by spray drying technique. A Quality by Design approach was applied for understanding the effect of the feed composition and spraying feed rate on typical quality attributes of inhalation powders. The in vitro aerodynamic behaviour of powders was evaluated using a medium resistance device. The inner structure and morphology of generated microparticles were also studied. The 1:4 ratio of CaPs/mannitol led to the generation of hollow microparticles, with the best aerodynamic performance. After microparticle dissolution, the released nanoparticles kept their original size.
\end{abstract}

Keywords: calcium phosphate nanoparticles; microparticles embedding nanoparticles; design of experiment; pulmonary delivery

\section{Introduction}

Rusconi et al. 2016 [1] have demonstrated that the cell-penetrating mimetic peptide (R7W-MP) targeting the $\mathrm{Ca}_{\mathrm{v}} \beta 2$ cytosolic subunit of the L-type calcium channel (LTCC) restored cardiac contractility in the pathological conditions of LTCC-based cardiomyopathy. 
However, the active Mimetic Peptide (MP) without the R7W cell-penetrating sequence loses the capability to enter the cardiac cells.

In a follow-up paper, the in vivo administration by nebulization of MP-loaded CaPs enabled their internalization into cardiomyocytes and restored cardiac function in a mouse model of cardiomyopathy [2]. Thus, this heart targeted treatment took advantage of the pulmonary administration route for cardiac accumulation of drug loaded CaPs.

However, drug loaded CaPs (hydrodynamic mean diameter $<200 \mathrm{~nm}$ ) present complexity for the administration by inhalation due to difficulty to control their nano size before and after delivery. One technological solution to achieve lung deposition of nanoparticles is their transformation into a microparticulate dry powder to inhale from a device [3]. In this case, their physical stability is improved, the dose control is more predictable, and the product could be used in home or care settings.

The research hypothesis underlying this work was to take advantage of the transient size of respirable microparticles obtained by embedding the nanoparticles in waterdissolving structures. Therefore, the aim was to study how to construct by spray drying inhalable microparticles embedding $\mathrm{CaP}$ nanoparticles for a deep lung deposition. Mannitol was selected as a soluble carrier, creating a matrix in which CaPs are homogeneously dispersed. Thus, microparticles in the respirable size range were prepared by spray-drying nanoparticle dispersions in an aqueous mannitol solution.

A Design of Experiments (DoE) toolbox was adopted for the identification of the Critical Process Parameters (CPPs) affecting the Critical Quality Attributes (CQAs) of respirable dry powders made of CaP nanoparticles embedded in microparticles [4]. Drying process yield, powder moisture content, microparticle size distribution, microparticle aerodynamic performance and size of released CaP nanoparticles were the CQAs [5].

A basic full factorial design was chosen to study the effects of selected input variables, i.e., the feed rate and $\mathrm{CaPs}$ and mannitol concentrations in the dispersion to spray dry.

\section{Materials and Methods}

\subsection{Materials}

$\mathrm{CaP}$ nanoparticles in water dispersion were prepared by a continuous flow process as reported in the paper of Degli Esposti et al. [6]. A pilot scale batch of three litres of unloaded CaPs was manufactured. The nanoparticle in dispersion had a concentration of $7.0 \mathrm{mg} / \mathrm{mL}$. $\mathrm{CaP}$ nanoparticles had a Z-average diameter of $80 \pm 15 \mathrm{~nm}$, a polydispersity index (PdI) of 0.2 , and a negative $\zeta$-potential of $-25 \pm 2 \mathrm{mV}$. The $\mathrm{Ca} / \mathrm{P}$ molar ratio, determined by inductively coupled plasma-optical emission spectrometry analysis, was $1.6 \pm 0.2$, in agreement with the typical value of nanocrystalline hydroxyapatite [7].

Mannitol (Ph.Eur.) was used as an excipient to manufacture microparticles.

\subsection{Methods}

\subsubsection{DoE for the Manufacturing of Microparticles Embedding Nanoparticles}

The manufacturing of spray-dried microparticles embedding unloaded CaPs was studied by applying a two-level full factorial design with 3 factors $\left(2^{3}\right)$, investigating all the possible combinations between the selected levels. This factorial design was kept as simple as possible for an initial screening of the factors effect on the quality of the final product. Therefore, a process manufacturing parameter and two critical material attributes were selected. These parameters relate to the future industrial production of powders and the structure of the microparticles. All statistically significant main effects and interactions of the input factors on the CQAs of the dry powder for inhalation were identified. In addition, three centre points were added to check for a possible curvature. The design was of resolution $\mathrm{V}$, meaning that there is no confounding effect between the main factors and their interactions. Thus, a total 11 experiments was generated and executed in a randomized way. The evaluation of the responses was performed both with relevant statistical graphs (Pareto charts) and ANOVA test (confidence interval: 95\%, desired power: 80-90\%, minimum variance: 0.0909). The significance of the mathematical model, as well 
as the impact of each input parameter on CQAs, were determined using the Design-Expert Software ${ }^{\circledR}$ Version 12 (Stat-Ease Inc., Minneapolis, MN, USA).

Practically, spray-dried microparticles for inhalation embedding unloaded CaPs were manufactured using a Büchi Mini Spray Dryer B-290 (Büchi Laboratory Equipment, Flawil, Switzerland). The aqueous dispersions to be dried were prepared starting from diluted nanoparticle dispersions to obtain the CaPs concentration reported in Table 1. Mannitol was dissolved in the CaPs dispersion to achieve the concentrations reported in Table 1. The dispersions were kept under magnetic stirring throughout the drying process. The spray drying feed rate was set accordingly to the values in Table 1 . The other spray drying operating parameters were fixed as follows: inlet temperature $125^{\circ} \mathrm{C}$, air flow rate $600 \mathrm{~L} / \mathrm{h}$, aspiration $35 \mathrm{~m}^{3} / \mathrm{h}$ and nozzle $0.7 \mathrm{~mm}$.

Table 1. Matrix of the full-factorial design.

\begin{tabular}{ccccc}
\hline Std & Run & $\begin{array}{c}\text { Factor A } \\
\text { CaPs Concentration } \\
(\mathbf{m g} / \mathbf{m L})\end{array}$ & $\begin{array}{c}\text { Factor B } \\
\text { Mannitol Concentration } \\
\text { (mg/mL) }\end{array}$ & $\begin{array}{c}\text { Factor C } \\
\text { Feed Rate } \\
\text { (mL/min) }\end{array}$ \\
\hline 4 & 1 & 7.00 & 2.00 & 3.50 \\
2 & 2 & 7.00 & 0.50 & 3.50 \\
3 & 3 & 0.50 & 2.00 & 3.50 \\
9 & 4 & 3.75 & 1.25 & 5.25 \\
1 & 5 & 0.50 & 0.50 & 3.50 \\
6 & 6 & 7.00 & 0.50 & 7.00 \\
5 & 7 & 0.50 & 0.50 & 7.00 \\
10 & 8 & 3.75 & 1.25 & 7.25 \\
7 & 9 & 0.50 & 2.00 & 7.00 \\
11 & 10 & 3.75 & 1.25 & 7.00 \\
8 & 11 & 7.00 & 2.00 & \\
\hline
\end{tabular}

The yield of the process was calculated using Equation (1):

$$
\text { Yield }=\frac{\mathrm{W}_{\mathrm{A}}}{\mathrm{W}_{\mathrm{T}}} * 100
$$

where $\mathrm{W}_{\mathrm{A}}$ is the weight of the powder recovered from the collection vessel and the cyclone, while $W_{T}$ is the weight of total solids in the dispersion to dry. Finally, the dry powders recovered were stored in a sealed glass vial at $25^{\circ} \mathrm{C}$.

\subsubsection{Microparticle Morphology by Scanning Electron Microscopy (FESEM-FIB)}

The microparticle morphology, surface texture and internal structure were investigated by a Field Emission Scanning Electron Microscope equipped with a Ga Focused Ion Beam (FIB) Auriga Compact (Zeiss, Jena, Germany). The samples were prepared by dispersing 1-2 mg of microparticles directly on the carbon tape placed on the aluminium stubs. The surface morphology and texture of the microparticles were investigated in plan-view by using a $1 \mathrm{kV}$ electron beam acceleration voltage. Such a low value allowed to analyze the microparticles without the need for metallization. To study the internal structure of microparticles embedding CaPs, the samples were tilted at $54^{\circ}$ with respect to plan-view zero-tilt condition. The particles were cut by FIB with an operating voltage of $30 \mathrm{kV}$ and a low current of $50 \mathrm{pA}$. The images of the microparticles cross-sections were acquired by using the same operating conditions selected for plan-view analysis. All the images were acquired with the Everhart-Thornley detector for secondary electrons.

\subsubsection{Microparticle Size Distribution by Laser Diffraction}

The particle size distribution (PSD) of powders was measured using the diffractometer Spraytec (Malvern Instruments Ltd., Worcestershire, UK) equipped with a $300 \mathrm{~mm}$ focal lens. Briefly, $10 \mathrm{mg}$ of powder was dispersed in $10 \mathrm{~mL}$ of cyclohexane (VWR International, 
France) containing $0.1 \%$ w/v of Span 85 (Merck KGaA, Darmstad, Germany). The dispersion was placed in an ultrasonic bath for $1 \mathrm{~min}$ and particle size distribution was measured with $5 \%$ threshold obscuration.

2.2.4. In Vitro Aerodynamic Assessment of Microparticles by Fast-Screening Impactor (FSI)

Next, $40 \mathrm{mg}$ of powder was introduced into HPMC QUALI-V I size 3 capsules (Qualicaps, Madrid, Spain). The loaded capsule was then inserted into the holder chamber of the RS01 ${ }^{\circledR}$ Medium Resistance Monodose Dry Powder Inhaler, (Plastiape, Lecco, IT). An abbreviated impactor (Fast Screening Impactor (FSI), Copley Scientific, Nottingham, UK) was employed for the powder separation in two fractions. In consideration of the monolithic structure of the mannitol microparticles, incorporating drug-free CaP nanoparticles, the adoption of the filter weighing procedure to determine the FPF values of powder aerosol with FSI was considered sufficiently accurate. The mass of fine microparticles weighed was in the order of tens of milligrams. Thus, a glass fibre filter, pre-weighed, was placed on the FSI Fine Fraction Collector (FFC) stage to recover the particles with an aerodynamic diameter lower than $5 \mu \mathrm{m}$. The assembled FSI was connected to a vacuum pump (Erweka GmbH, Langen, DE). The dry powder inhaler with capsule was weighed and the capsule pierced. An aspiration flow rate of $60 \mathrm{~L} / \mathrm{min}$ was applied for $4 \mathrm{~s}$ (Copley Scientific, Nottingham, UK) at a pressure drop of $4 \mathrm{kPa}$ over the inhaler, to aerosolize the capsule content. After aerosolization, the FFC filter holder was disassembled and the filter carefully transferred into a plastic Petri dish. Then, the filter, as well as the system device-capsule, were weighed in a balance (limit $10 \mathrm{mcg}$ ). The difference between the filter weight before and after device actuation provides the Emitted Dose (ED) which expresses the amount of powder that left the device. The ratio between the ED and metered dose defines the Emitted Fraction (EF). Finally, the weight of the powder deposited on the FFC filter is the Fine Particle Dose (FPD) of the powder (aerodynamic diameter $<5 \mathrm{~mm}$ ), while the ratio of the FPD with the ED gives the Fine Particle Fraction (FPF). ED, EF, FPD and FPF are indicators of the powder aerodynamic performance.

\subsubsection{Density Measurement}

The true density of powders was measured with AccuPyc II 1340 gas pycnometer (Micromeritics Instrument Corporation, Norcross, GA, USA). Bulk and tapped densities were determined following Ph. Eur. 10th ed. Three measurements were performed for each sample.

\subsubsection{Thermogravimetric Analysis (TGA)}

Thermogravimetric analysis for the calculation of the residual solvent content of powders was performed with a TGA equipment (METTLER Toledo, Worthington, OH, USA). For the purpose, 3-5 mg of each spray-dried powder was accurately weighed in a $70 \mu \mathrm{L}$ alumina pan with a pierced cover (crucibles). The analysis was done by heating the sample under a flux of dried nitrogen $(80 \mathrm{~mL} / \mathrm{min})$ from $25^{\circ} \mathrm{C}$ to $150{ }^{\circ} \mathrm{C}$ at a rate of $10{ }^{\circ} \mathrm{C} / \mathrm{min}$.

2.2.7. Dimensional Analysis and Surface Charge of Released Nanoparticles by Dynamics Light Scattering

A protocol for CaP nanoparticle release from microparticles was established to evaluate the influence of the spray drying procedure and microparticle composition on the properties of released CaPs. An amount of powder was dissolved with gentle shaking in ultrapure water. Z-average diameter, Polydispersity Index and $\zeta$-potential were determined using Dynamic Light Scattering (DLS) Zetasizer Nano ZS (Malvern Instruments Ltd., Worcestershire, UK). 


\section{Results and Discussion}

\subsection{DoE Analysis of Microparticle Manufacturing}

The objective of the DoE process was to study the production of microparticulate powders and to assess in vitro their features for the deposition in the deep lung and for the nanoparticle release in a size comparable to the original. Mannitol was selected as the carrier that could provide an efficient nanoparticles re-dispersion of nanoparticles after excipient dissolution.

CaPs and mannitol concentrations were the formulation factors selected. In fact, the aerodynamic behaviour of microparticles depends on the solid structure obtained following solvent evaporation. In consideration of its relevance for the industrial manufacturing time, the feed rate of the liquid to dry was selected as a process parameter.

To evaluate the prepared powders within the quality by design framework, the CQAs considered were the process yield, moisture content, microparticle size distribution (median volume diameter, $\mathrm{D}_{\mathrm{v} 50}$ ) and aerodynamic performance, expressed as Emitted Dose and Fine Particle Dose. The hydrodynamic diameter $\left(\mathrm{d}_{\mathrm{H}}\right)$ of the nanoparticles, released upon microparticle dissolution, was measured as well.

Thus, a full factorial experimental design was chosen by combining three factors at two levels. In total, eleven experiments (eight factorials and three central repetitions) were generated in a randomized way to avoid bias. The process and composition factors with their corresponding levels are reported in Table 2.

The corresponding CQAs of the produced microparticles, replicated three times, are also shown in Table 2 for all the eleven formulations prepared. The low, middle, and high levels of the factors are designated with $-1,0$, and +1 , respectively. The three centre points of experiments correspond to Runs 4, 8, and 10 .

Table 2. Summary of the selected factors with the coded representation and responses of the eleven powders prepared.

\begin{tabular}{cccccccccc}
\hline & \multicolumn{7}{c}{ Factors } & \multicolumn{7}{c}{ Responses } \\
\hline Run & $\begin{array}{c}\mathbf{A} \\
\mathbf{C a P s} \\
(\mathbf{m g} / \mathbf{m L})\end{array}$ & $\begin{array}{c}\mathbf{B} \\
\mathbf{M a n n i t o l} \\
(\mathbf{m g} / \mathbf{m L})\end{array}$ & $\begin{array}{c}\text { Feed Rate } \\
(\mathbf{m l} / \mathbf{m i n})\end{array}$ & $\begin{array}{c}\text { Yield } \\
\mathbf{( \% )}\end{array}$ & $\begin{array}{c}\text { Moisture } \\
\text { Content } \\
\mathbf{( \% )}\end{array}$ & $\begin{array}{c}\text { Z-Average } \\
\text { Diameter } \\
(\mathbf{n m})\end{array}$ & $\begin{array}{c}\mathbf{D}_{\mathbf{v} 50} \\
(\boldsymbol{\mu m})\end{array}$ & $\begin{array}{c}\text { ED } \\
(\mathbf{m g})\end{array}$ & $\begin{array}{c}\text { FPD } \\
(\mathbf{m g})\end{array}$ \\
\hline 1 & +1 & +1 & -1 & 84.4 & $1.2 \pm 0.1$ & $313.4 \pm 7.0$ & $3.0 \pm 0.1$ & $38.1 \pm 0.2$ & $11.8 \pm 0.2$ \\
2 & +1 & -1 & -1 & 62.5 & $1.3 \pm 0.1$ & $1787.0 \pm 15.0$ & $2.1 \pm 0.1$ & $33.0 \pm 0.4$ & $17.0 \pm 0.3$ \\
3 & -1 & +1 & -1 & 58.4 & $1.5 \pm 0.1$ & $85.4 \pm 6.0$ & $1.6 \pm 0.1$ & $32.1 \pm 0.3$ & $23.8 \pm 0.4$ \\
4 & 0 & 0 & 0 & 85.0 & $3.2 \pm 0.2$ & $400.0 \pm 7.0$ & $2.6 \pm 0.2$ & $34.0 \pm 0.2$ & $20.0 \pm 0.3$ \\
5 & -1 & -1 & -1 & 53.2 & $4.0 \pm 0.2$ & $839.5 \pm 6.0$ & $3.1 \pm 0.1$ & $34.6 \pm 0.3$ & $24.3 \pm 0.2$ \\
6 & +1 & -1 & +1 & 75.2 & $3.6 \pm 0.1$ & $1992.0 \pm 21.0$ & $3.3 \pm 0.2$ & $37.6 \pm 0.2$ & $12.9 \pm 0.2$ \\
7 & -1 & -1 & +1 & 34.4 & $3.2 \pm 0.1$ & $957.4 \pm 4.0$ & $2.3 \pm 0.2$ & $31.5 \pm 0.2$ & $16.2 \pm 0.3$ \\
8 & 0 & 0 & 0 & 72.2 & $2.8 \pm 0.1$ & $892.0 \pm 8.0$ & $3.0 \pm 0.1$ & $32.2 \pm 0.1$ & $23.4 \pm 0.3$ \\
9 & -1 & +1 & +1 & 61.8 & $1.4 \pm 0.1$ & $428.0 \pm 7.0$ & $2.8 \pm 0.2$ & $35.6 \pm 0.1$ & $15.4 \pm 0.3$ \\
10 & 0 & 0 & 0 & 85.0 & $2.5 \pm 0.2$ & $423.0 \pm 6.0$ & $2.9 \pm 0.1$ & $32.7 \pm 0.2$ & $24.3 \pm 0.2$ \\
11 & +1 & +1 & +1 & 81.8 & $1.5 \pm 0.2$ & $418.4 \pm 10.0$ & $3.5 \pm 0.1$ & $37.1 \pm 0.4$ & $15.4 \pm 0.4$ \\
\hline
\end{tabular}

\subsubsection{Yield of the Spray Drying Process}

As per Table 2, the yield of the process varied from 34.4 to $85.0 \%$, which reveals an important dependence from the levels of the selected factors. ANOVA test shows a significant effect by both formulation factors, i.e., CaPs and mannitol concentrations (Table 3). In contrast, the process factor feed rate (factor C) was not significant, thus excluded from the analysis. More specifically, as illustrated in the Pareto chart of Figure 1, by increasing the concentration of CaPs (factor A) and mannitol (factor B), the yield was positively affected. Similarly, Dormenval et al. referred that, among the factors of importance for the manufacturing of spray-dried siRNA-loaded lipid nanoparticles for inhalation, higher feedstock concentrations increased the yield [8].

The yield was essentially affected by the sticking of particles to the drying chamber, cyclone walls and filter [9]. Finally, it must be underlined that the yield is not always an 
easy to interpret response. For instance, higher order models may govern the effect of the selected factors on the yield [10].

Table 3. ANOVA results for the selected factorial model for the yield of the spray drying process.

\begin{tabular}{ccccccc}
\hline Source & Sum of Squares & df & Mean Square & F-Value & $p$-Value \\
\hline Model & 1621.05 & 2 & 810.53 & 15.02 & 0.0029 & significant \\
A-CaPs conc. & 1154.40 & 1 & 1154.40 & 21.39 & 0.0024 \\
B-Mannitol conc. & 466.65 & 1 & 466.65 & 8.65 & 0.0217 \\
Curvature & 613.66 & 1 & 613.66 & 11.37 & 0.0119 \\
Residual & 377.85 & 7 & 53.98 & & 0.5738 & not significant \\
Lack of Fit & 268.63 & 5 & 53.73 & & \\
Pure Error & 109.23 & 2 & 54.61 & & \\
Cor Total & 2612.57 & 10 & & & \\
\hline
\end{tabular}

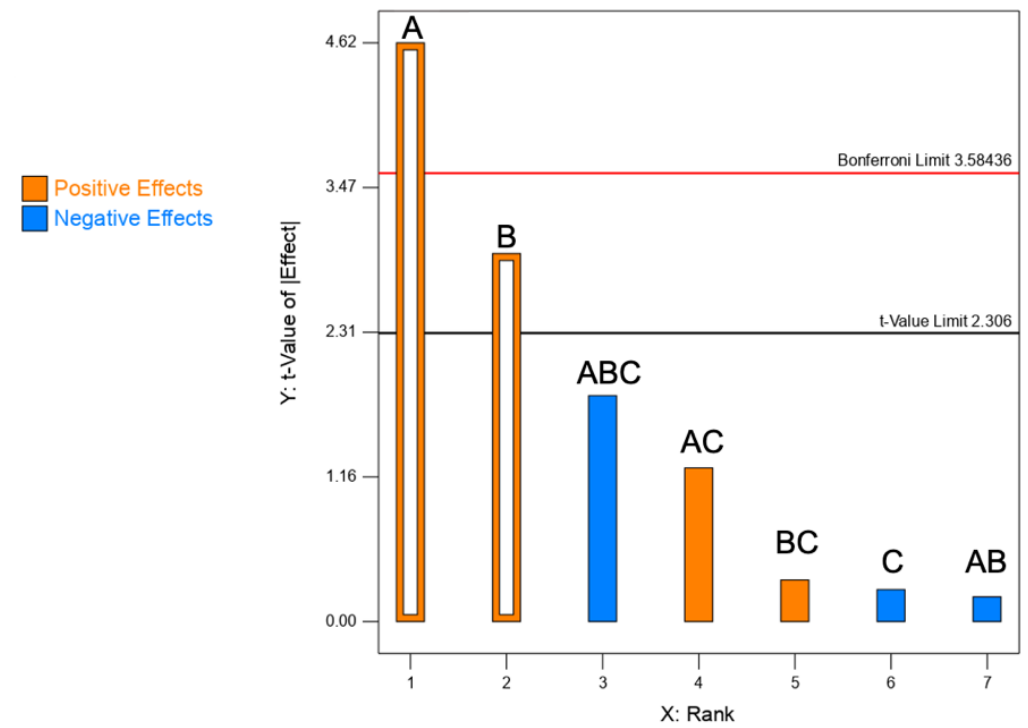

Figure 1. Pareto chart illustrating the rank of the $t$-values corresponding to the effect on spray drying yield of each factor and their interactions (empty bars: significant; full bars: non-significant). Blue bars = negative effects; orange bars $=$ positive effects. A: CaPs concentration.; B: mannitol concentration; $\mathrm{C}$ : feed rate. The red line corresponds to the Bonferroni limit and the black one to the $\mathrm{t}$-value limit.

\subsubsection{Moisture Content}

The measured moisture contents of the 11 powders produced are shown in Table 2.

The moisture content has been selected as CQA since it favours the agglomeration of very small particles, worsening powder flow properties, and affecting aerosolization. Moreover, it could also influence long-term physical and chemical stability [11]. In this study, the moisture content of all powders ranged between 1.2 and $4.0 \%(w / w)$. The lowest value of moisture content was achieved at a high level of mannitol concentration; mannitol is known to be a non-hygroscopic substance. Conversely, the highest moisture was obtained at a low level of mannitol.

Indeed, the Pareto chart (Figure 2) illustrates the level of significance of mannitol concentration in decreasing the moisture content of the dry powder formulations. The ANOVA test shows that the factors CaPs concentration and feed rate factors did not significantly affect the moisture content. (Table 4). 


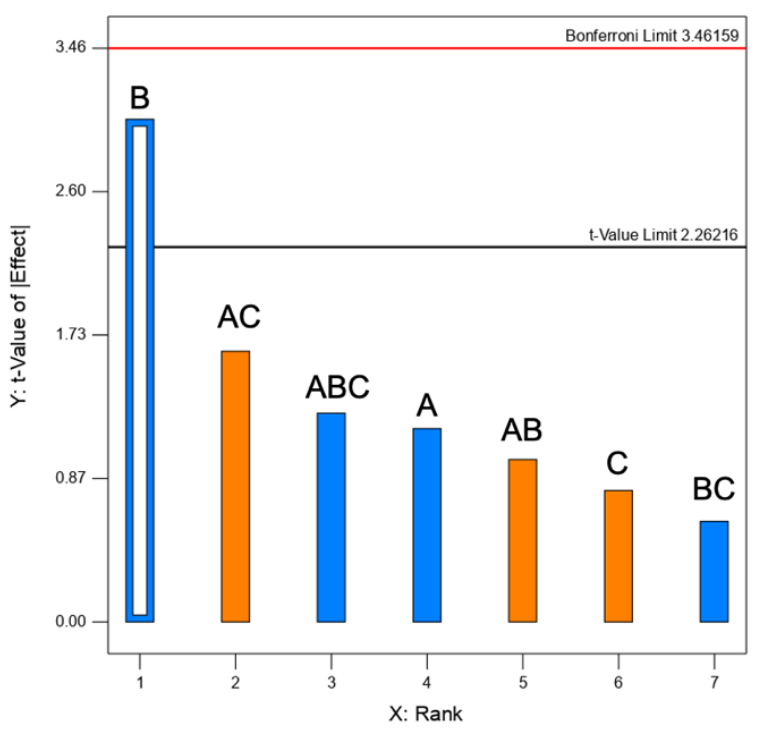

Figure 2. Pareto chart illustrating the rank of the $t$-values corresponding to the effect of each factor on moisture content. Empty bars: significant; full bars: non-significant. Blue bars = negative effects; orange bars = positive effects. A: CaPs conc.; B: mannitol conc.; $\mathrm{C}$ : feed rate. The red line corresponds to the Bonferroni limit and the black one to the $\mathrm{t}$-value limit.

Table 4. ANOVA results for the moisture content of microparticles embedding nanoparticles.

\begin{tabular}{cccccc}
\hline Source & Sum of Squares & df & Mean Square & F-Value & $p$-Value \\
\hline Model & 5.28 & 1 & 5.28 & 9.20 & 0.0162 \\
B-Mannitol conc. & 5.28 & 1 & 5.28 & 9.20 & 0.0162 \\
Curvature & 0.84 & 1 & 0.84 & 1.46 & 0.2608 \\
Residual & 4.59 & 8 & 0.57 & & significant \\
Lack of Fit & 4.35 & 6 & 0.72 & 5.88 & 0.1526 \\
Pure Error & 0.25 & 2 & 0.12 & & not significant \\
Cor Total & 10.72 & 10 & & & \\
\hline
\end{tabular}

\subsubsection{Particle Size Distribution of Microparticulate Dry Powders}

Particle size distribution of inhalation dry powders is one of the three characteristics determining the particle aerodynamic behaviour together with size, density and shape. The prepared dry powders showed $D_{v 50}$ between $1.6 \mu \mathrm{m}$ and $3.5 \mu \mathrm{m}$, a range considered suitable for particle inhalation [12]. The highest $\mathrm{Dv}_{50}$ value resulted when the solid concentration of feed solution and the feed rate were at their maximum levels (Run 11). Conversely, the lowest $D_{v 50}$ value was measured when the factors CaP concentration and feed rate were at low values, with the mannitol concentration at its high value (Run 3).

Other authors pointed out [13] that the geometric size $\left(\mathrm{d}_{\mathrm{g}}\right)$ of the drying particle in relation to droplet solvent evaporation, is described by Equation (2):

$$
\mathrm{d}_{\mathrm{g}}=\sqrt[3]{\frac{\mathrm{c}_{\mathrm{f}}}{\rho_{\mathrm{p}}}} \mathrm{d}_{\mathrm{D}}
$$

where $c_{f}$ is the feed solution concentration, $\rho_{p}$ the particle density and $d_{D}$ the droplet size. Droplet size was expected to be affected by increasing the feed rate since more liquid is dispersed at the nozzle. Thus, the increase in feed solution concentration and in droplet size due to high feed rate, led to larger dried particles, depending on the particle density. In addition, the increase of feed rate leads to lower outlet temperature which results in lower drying efficiency, generating larger particles as well. However, examining the ANOVA test results (Table 5), the model was found not significant ( $p$ value: 0.859$)$. Likely, the variation of the output in terms of particle size was minimally influenced by the selected factors 
and their ranges. We attempted also to examine other size distribution parameters, i.e., $\mathrm{Dv}_{90}$ or Span, but in neither case the model was significant. In summary, the values of $\mathrm{Dv}_{50}$ are quite small, meaning that the PSD of the microparticle is a robust parameter in the manufacturing ranges selected.

Table 5. ANOVA results for the selected factorial model for $\mathrm{D}_{\mathrm{v} 50}$.

\begin{tabular}{cccccc}
\hline Source & Sum of Squares & df & Mean Square & F-Value & $p$-Value \\
\hline Model & 0.95 & 5 & 0.18 & 0.35 & 0.8590 \\
A-CaPs conc & 0.03 & 1 & 0.03 & 0.06 & 0.8214 \\
B-Mannitol conc & 0.00 & 1 & 0.00 & 0.02 & 0.8920 \\
C-Feed rate & 0.00 & 1 & 0.00 & 0.00 & 0.9639 \\
AC & 0.45 & 1 & 0.45 & 0.84 & 0.4116 \\
BC & 0.45 & 1 & 0.45 & 0.84 & 0.4116 \\
Curvature & 0.00 & 1 & 0.00 & 0.01 & 0.9051 \\
Residual & 2.15 & 4 & 0.54 & 0.11 & 0.9013 \\
Lack of Fit & 0.21 & 2 & 0.11 & & not significant \\
Pure Error & 1.94 & 2 & 0.97 & & \\
Cor Total & 3.11 & 10 & & & \\
\hline
\end{tabular}

\subsubsection{Aerodynamic Performance of Spray Dried Powders}

The Critical Quality Attributes selected to assess the in vitro powder aerodynamic performance of the powders were the Emitted Dose and the Fine Particle Dose. According to European Pharmacopeia, the Emitted Fraction should be not less than $75 \%$ of the dose metered in the device that, in this case, was $40.0 \pm 0.5 \mathrm{mg}$. As reported in Figure 3, in all powders EF was higher than $75 \%$. This means that all the formulations possessed favourable flow properties for aerosolization. However, the Emitted Dose response showed a non-significant effect of all the factors selected, thus ED was not further considered.

The fine particle aerodynamic size distribution is the indicator of the deposition behaviour of particles in the lung. Particles with a mean aerodynamic diameter between 1 to $5 \mu \mathrm{m}$ are considered respirable [14]. FPD value measures the mass of aerosolized particles having an aerodynamic diameter lower than $5 \mu \mathrm{m}$. As it can be noticed in Table 2, FPD ranges from 11.8 to $24.3 \mathrm{mg}$, corresponding to Fine Particle Fraction of $31 \%$ and $74.3 \%$, respectively (Figure 3).

Emitted Fraction (\%)

- Fine Particle Fraction (\%)

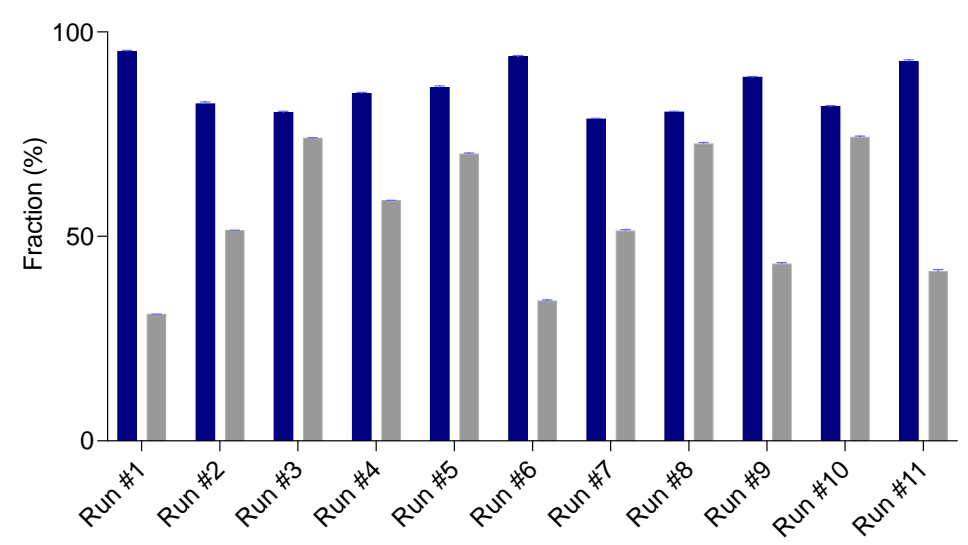

Figure 3. Emitted and Fine Particle Fraction of the eleven powders manufactured.

The results of the ANOVA test (Table 6) shows that A (CaP concentration), $\mathrm{C}$ (feed rate) and their interaction $A C$ are significant factors for respirability. The other terms $(B$, $\mathrm{AB}, \mathrm{BC}, \mathrm{ABC}$ ) are insignificant and were not included in the model. 
Table 6. ANOVA results for the selected factorial model for FPD.

\begin{tabular}{|c|c|c|c|c|c|c|}
\hline Source & Sum of Squares & df & Mean Square & F-Value & $p$-Value & \\
\hline Model & 131.97 & 3 & 43.99 & 9.64 & 0.0104 & significant \\
\hline A-CaPs conc & 63.84 & 1 & 63.84 & 13.99 & 0.0096 & \\
\hline C-Feed rate & 36.12 & 1 & 36.13 & 7.92 & 0.0306 & \\
\hline $\mathrm{AC}$ & 32.00 & 1 & 32.00 & 7.01 & 0.0381 & \\
\hline Curvature & 65.20 & 1 & 65.20 & 14.29 & 0.0092 & \\
\hline Residual & 27.38 & 6 & 4.56 & & & \\
\hline Lack of Fit & 17.09 & 4 & 4.27 & 0.83 & 0.6103 & not significant \\
\hline Pure Error & 10.29 & 2 & 5.14 & & & \\
\hline Cor Total & 224.55 & 10 & & & & \\
\hline
\end{tabular}

Individually, factors $\mathrm{A}$ and $\mathrm{C}$ have a significant negative effect, that is a reduction of the fine particle dose, whereas their interaction has a positive effect (Pareto chart, Figure 4). Despite this was a curious situation, it is possible that two negative effects turn into a positive effect when they interact in the system. These results differ from those obtained from the PSD analysis, where the non-significant correlation of factors with geometric size was found. Besides geometric size, particle density and shape have a relevant impact on aerodynamic size and, subsequently, on FPD $[15,16]$. As an example, even though the powder of Run 5 has a $D_{v 90}$ of $7.7 \mu \mathrm{m}$, it exhibited the highest FPD value $(24.3 \mathrm{mg})$; conversely, despite a more favourable $\mathrm{D}_{\mathrm{v} 90}$, the powder of Run $1\left(\mathrm{D}_{\mathrm{v} 90} 5.5 \mu \mathrm{m}\right)$ showed the lowest FPD $(11.8 \mathrm{mg})$.

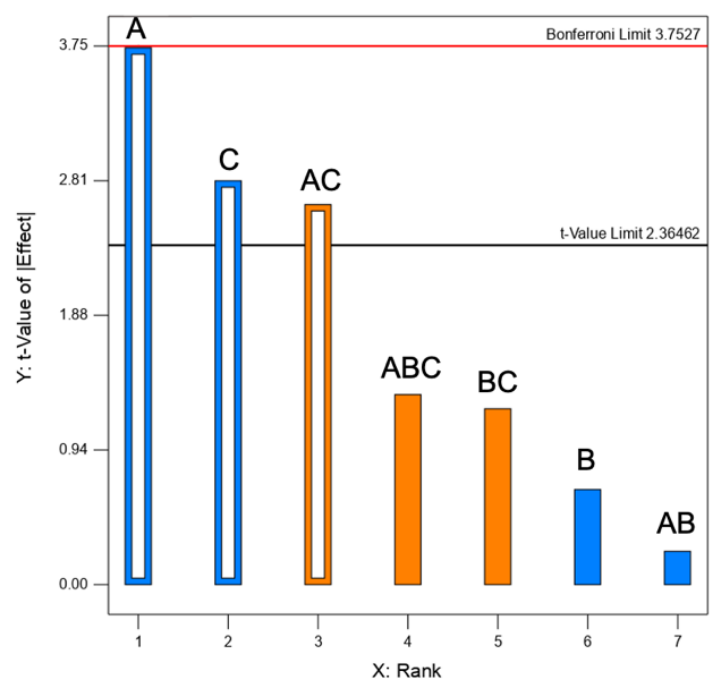

Figure 4. Pareto chart illustrating the rank corresponding to the effect of each factor on the FPD. Empty bars: significant; full bars: non-significant. Blue bars = negative effects; orange bars = positive effects. A: CaPs conc.; B: mannitol conc.; C: feed rate. The red line corresponds to the Bonferroni limit and the black one to the $t$-value limit.

\subsubsection{Z-Average of Nanoparticles Released in Water}

Nanoparticle hydrodynamic diameter, $\mathrm{d}_{\mathrm{H}}$, recovered after microparticle dissolution is one of the critical quality attributes of this product. Thorley A. et al. [17] and Islam M.A et al. [18] have shown that the lower the $\mathrm{d}_{\mathrm{H}}$, the easier the nanoparticle uptake by the cell. An in vitro test to assess the quality of the nanoparticles released from the dissolved microparticles was carried out. It is worth mentioning that this test did not aim to mimic the release of nanoparticles in vivo from inhaled microparticles deposited on the wet lung epithelium. Particle sizes of CaPs dispersion after microparticle dissolution in water are reported in Table 2. The results of the ANOVA test (Table 7) show a significant effect of the formulation factors $\mathrm{CaPs}$ and mannitol concentrations, together with their interaction. In contrast, the feed rate was insignificant, thus removed from the model. 
Table 7. ANOVA results for the selected factorial model for Z-average diameter.

\begin{tabular}{cccccc}
\hline Source & Sum of Squares & df & Mean Square & F-Value & $p$-Value \\
\hline Model & $3.339 \times 10^{6}$ & 3 & $1.113 \times 10^{6}$ & 27.10 & 0.0007 \\
A-CaPs conc. & $6.053 \times 10^{5}$ & 1 & $6.053 \times 10^{5}$ & 14.74 & 0.0086 \\
B-Mannitol conc. & $2.344 \times 10^{6}$ & 1 & $2.344 \times 10^{6}$ & 57.10 & 0.0003 \\
AB & $3.888 \times 10^{5}$ & 1 & $3.888 \times 10^{5}$ & 9.47 & 0.0217 \\
Curvature & $1.722 \times 10^{5}$ & 1 & $1.722 \times 10^{5}$ & 4.19 & 0.0865 \\
Residual & $2.644 \times 10^{5}$ & 6 & 41060.16 & & 0.8600 \\
Lack of Fit & 92176.29 & 4 & 23044.07 & 0.30 & not significant \\
Pure Error & $1.542 \times 10^{5}$ & 2 & 77092.33 & & \\
Cor Total & $3.757 \times 10^{6}$ & 10 & & & \\
\hline
\end{tabular}

In the Pareto chart (Figure 5), the increase of CaPs concentration in the liquid feed (factor A) shows a positive effect, i.e., the size of the released nanoparticles rises. In contrast, the increase of mannitol concentration (factor B) exhibits a very significant negative effect, i.e., the size of released nanoparticles remains small. Since the CaPs size depends on nanoparticle agglomeration, the presence of mannitol reduces the likelihood of direct contact between adjacent nanoparticles. The polyol fills the space among the nanoparticles, enlarging the interparticle distance limiting the attractive forces. Thus, a high mannitol concentration helps to preserve the original size of CaPs nanoparticles. Keil et al. [19] formulated the hypothesis that a large amount of water lost from the nanoparticles' dispersion during the spray drying process, may lead to the need for larger amounts of matrix/filler excipients.

In addition, a significant interaction between factors A and B was measured. In fact, the Pareto chart (Figure 5) showing the beneficial negative effect of $A B$ interaction on the nanoparticle size upon release from the microparticles, supports the dependence of restored size on the CaPs and mannitol concentration ratio.

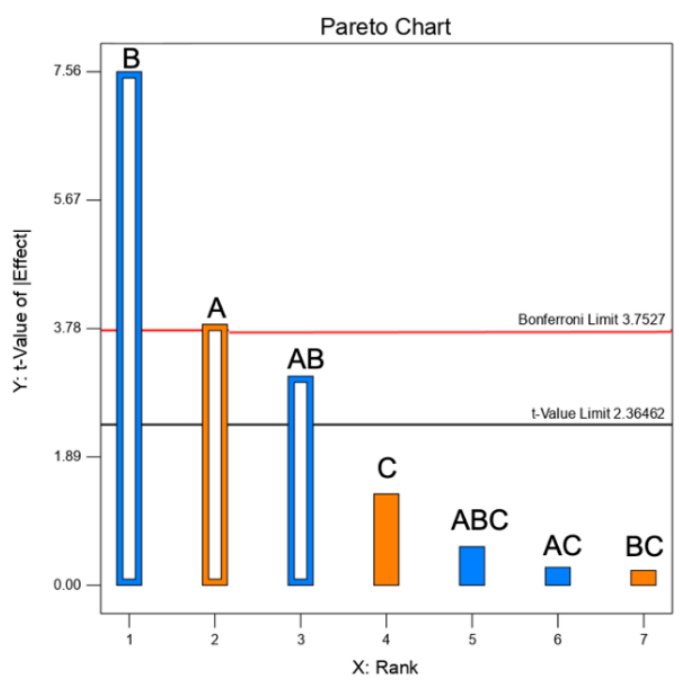

Figure 5. Pareto chart illustrating the rank corresponding to the effect of each factor on the Zaverage diameter of restored nanoparticles. Empty bars: significant; full bars: non-significant. Blue bars = negative effects; orange bars = positive effects. A: CaPs conc.; B: mannitol conc.; C: feed rate. The red line corresponds to the Bonferroni limit and the black one to the $t$-value limit.

As the interaction between the two formulation factors (AB) was significant (Figure 5), we deduced that the relevant parameter for $\mathrm{CaP}$ nanoparticle size maintenance is the ratio between mannitol and nanoparticle amount. In fact, the highest size value of the released nanoparticles was measured when the ratio between nanoparticles and mannitol was 14:1, whereas the original small size of nanoparticles was maintained at the ratio 1:4. 
Together with the nanoparticle size, for sake of completeness, we reported in the Supplementary material (Table S1) the polydispersity index and $\zeta$-potential values. $\zeta$ potential ranged from -13.0 to $-21.2 \mathrm{mV}$, confirming the achievement of relatively stable colloidal systems.

\subsection{Particle Morphology of DoE Powders}

To understand the mechanisms of microparticle aerodynamics and nanoparticle release behaviour, i.e., the two most relevant characteristics for the heart targeting by inhalation of nanoparticles, it is imperative to look at their microscopical structure. The scanning electron microscopy coupled with a focused ion beam was used to visualize the particle size, shape, surface morphology and internal structures of microparticles. These micromeritic properties are key factors impacting on flow, dispersibility, and aerodynamic behaviour particle size of dry powders.

Beforehand, mannitol alone was spray-dried and the resulting particles examined to understand the impact of the polyol on particle structure. Then, powders from Runs 2, 3, and 5 , were considered because they were very different from the others.

In Figure 6, SEM/FIB images illustrate plan-view and cross-section of FIB-cut microparticles of spray-dried mannitol alone. The dimensional range of the particles is between $200 \mathrm{~nm}$ and $1 \mu \mathrm{m}$, a quite narrow PSD. Their shape is rather spherical with a smooth surface. Similar morphology of mannitol microparticles has been described elsewhere [20]. In addition, FIB-cut allows observing the internal structure of these particles (Figure 6, right). The particle is hollow with a centred large cavity of around $1.0 \mu \mathrm{m}$, whereas the structure of the wall is dense and homogeneous.
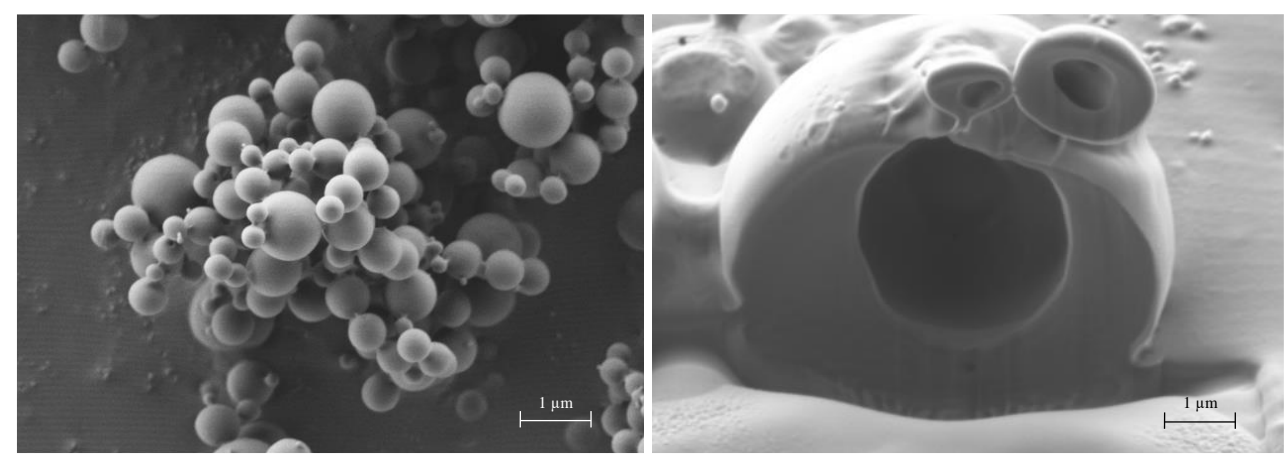

Figure 6. SEM plan-view micrograph of spray-dried mannitol microparticles (left) and cross-section of FIB-cut mannitol particle (right).

When CaPs were added, their ratio to mannitol in the dispersion to spray dry changed the morphology of the resulting mannitol microparticles, now embedding CaPs. Torge et al. [21] investigated the morphology and aerodynamic properties of spray-dried mannitol microparticles embedding polylactic-co-glycolic acid nanoparticles at three different ratios. They found that mannitol content influenced morphology, nevertheless, all powders were suitable for pulmonary delivery.

In Figure 7, particle shape, surface morphology and internal structure of microparticles from Run 3 (CaPs concentration $0.5 \mathrm{mg} / \mathrm{mL}$; mannitol $2.0 \mathrm{mg} / \mathrm{mL}$; feed rate: $3.5 \mathrm{~mL} / \mathrm{min}$ ) are displayed. The CaPs:mannitol ratio was 1:4. In this case, the microparticles had $\mathrm{D}_{\mathrm{v} 10}$, $1.3 \mu \mathrm{m}$ and $\mathrm{D}_{\mathrm{v} 90}$ of $3.1 \mu \mathrm{m}$ as volume diameter. The particle shape is spherical and close to that of spray-dried mannitol. However, the particle surface appears rougher, while the structure still exhibits an internal cavity. Differently, small pores are present in the wall around the cavity. An increase in the particle porosity leads to a decrease in particle density that reduces the aerodynamic particle size. The true density of this powder was $1.590 \pm 0.002 \mathrm{~g} / \mathrm{cm}^{3}$ and the apparent tapped density was $0.750 \pm 0.002 \mathrm{~g} / \mathrm{cm}^{3}$. Although the measured value of tapped density was higher than the $0.4 \mathrm{~g} / \mathrm{cm}^{3}$ limit value according to Chougule et al. [22], respirable particles were prepared with this ratio of components. 

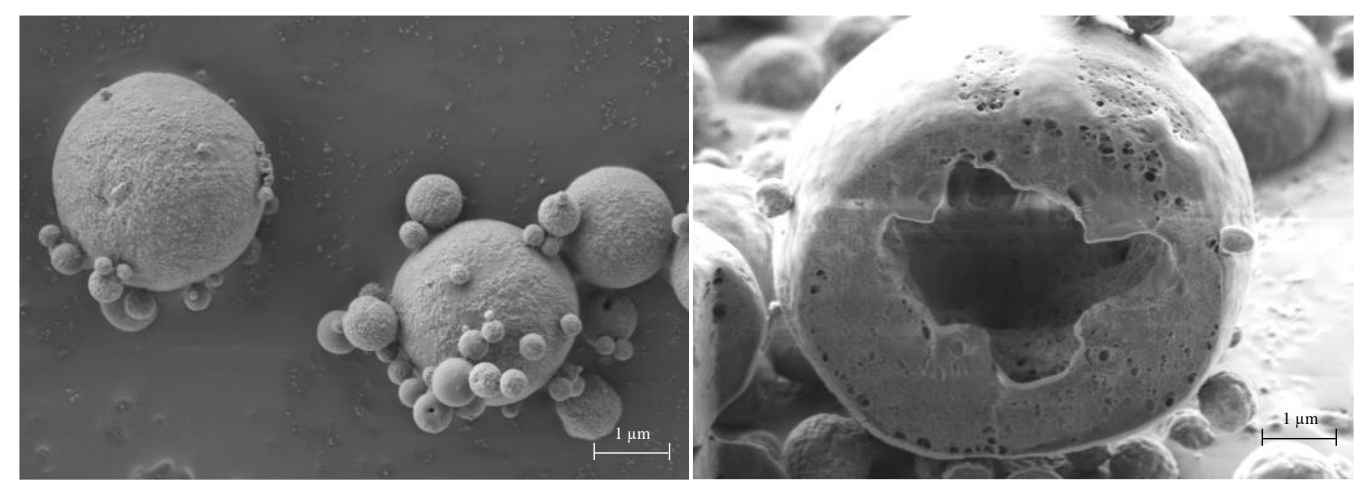

Figure 7. SEM plan-view micrograph of spherical microparticles embedding calcium phosphate nanoparticles from Run 3 (left) and cross-section of FIB-cut particle (right). Ratio CaPs: mannitol 1:4.

In Run 2 , a feed solution containing $0.5 \mathrm{mg} / \mathrm{mL}$ of mannitol dissolved in the dispersion containing $7.0 \mathrm{mg} / \mathrm{mL}$ of nanoparticles was dried at a feed rate of $3.5 \mathrm{~mL} / \mathrm{min}$. In Figure 8 , SEM micrographs at different magnifications show microparticles with different sizes and shapes, mostly below $5 \mu \mathrm{m}$. Most of them are spheroidal, typical of particles prepared by spray drying [23]. However, doughnut-shaped structures of spray-dried microparticles (Figure 8) appeared in this composition in which nanoparticle concentration was high and mannitol low. Depending on their size, some microparticles have collapsed during formation. In fact, the larger particles show a central hole which makes them resemble a doughnut [24].

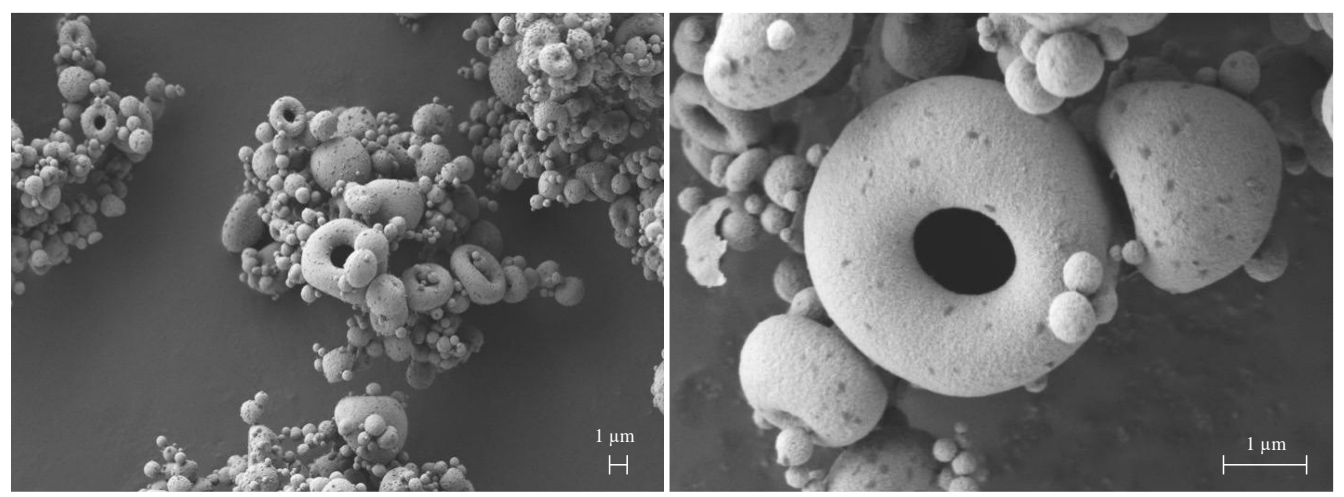

Figure 8. SEM plan-view micrographs of doughnut-shaped microparticles CaPs: mannitol 14:1 embedding unloaded calcium phosphate nanoparticles (Run 2).

We speculated that the increase of nanoparticle fraction in the composition leads to a high Péclet number, i.e., the ratio of solvent evaporation rate (k) and diffusion coefficient of solute component $i$ in liquid phase $\left(\mathrm{D}_{\mathrm{i}}\right)$, as shown in Equation (3) [25].

$$
\mathrm{Pe}_{\mathrm{i}}=\frac{\mathrm{k}}{8 \mathrm{D}_{\mathrm{i}}}
$$

This dimensionless number is calculated from the ratio between the droplet surface area shrinking rate during drying and the rate of solute diffusion (nanoparticles and mannitol molecules) from the air/liquid interface to the droplet centre [26]. $P_{\mathrm{e}}$ drives the microparticle structure to be a dense, or rather hollow "empty particle" (Figure 9). Calcium phosphate nanoparticles have a diffusion coefficient in water lower than mannitol $\left(2.7 \times 10^{-7} \mathrm{~cm}^{2} / \mathrm{s}\right.$ vs. $\left.2.9 \times 10^{-6} \mathrm{~cm}^{2} / \mathrm{s}\right)[27,28]$ Therefore, during droplet evaporation, a porous shell of nanoparticles is formed, allowing the residual core solvent to evaporate. 


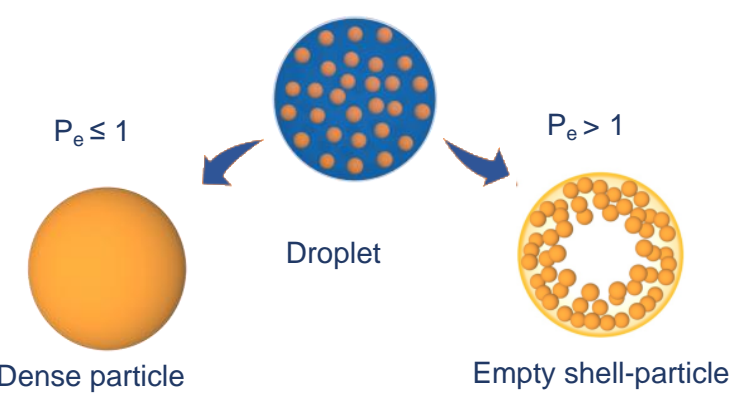

Figure 9. Drying of droplets containing particles of low (left) and high (right) Péclet number.

In this case, the morphology of the dried particles depends on the chemical nature, concentration, mechanical properties of the materials forming the shell, and the nanoparticle colloidal interactions $[29,30]$. The accumulation of nanoparticles at the particle surface during drying, in presence of a low amount of mannitol, weakened the resistance of the shell curvature. Depending on size, the particle in formation resists and remains spherical or collapses to form the hollow structures shown in Figure 8. However, the doughnut-like microparticle structures exhibited acceptable respirability, lower than spherical particles, still with a Fine Particle Fraction higher than 50\%. Conversely, once dissolved in water, the doughnut-shaped microparticles released nanoparticles of increased size owing to the presence of clusters, deriving from the higher concentration of nanoparticles compared to mannitol (components' ratio 14:1).

In Figure 10, SEM pictures from Run 5 powder obtained with a CaPs:mannitol ratio of 1:1 are shown.
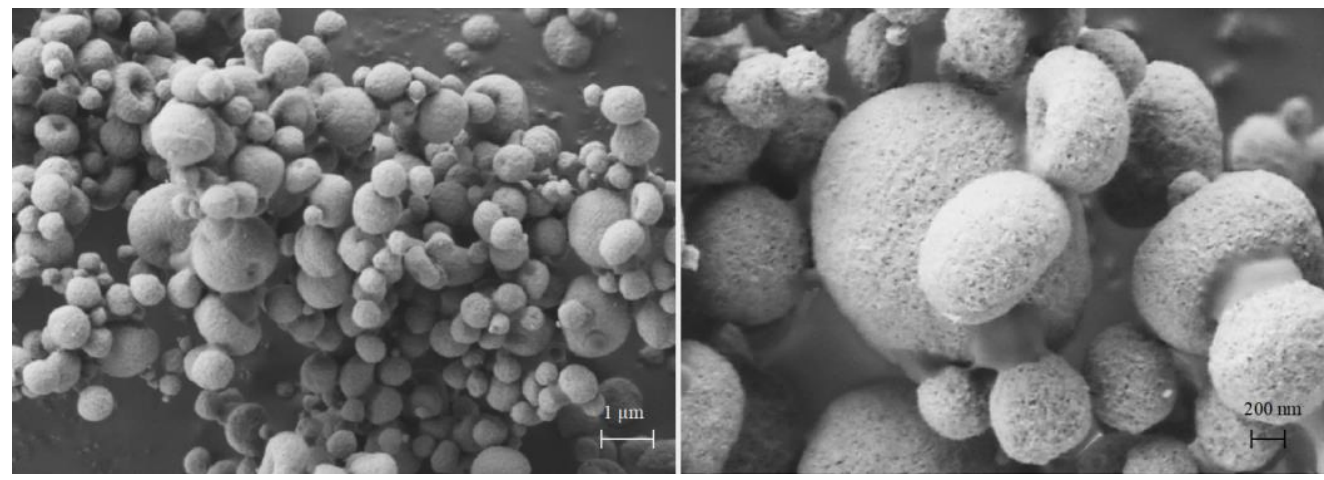

Figure 10. SEM plan-view micrographs of spray-dried microparticles from Run 5 embedding unloaded nanoparticles, ratio CaPs: mannitol 1:1.

In this case, particles show a rough surface and dimpled shape due to an incomplete doughnut formation. The higher amount of mannitol in the composition makes the shell formed during drying more resistant, compared to microparticles of Figure 8 . The results confirm the effect of the CaPs and mannitol ratio on the resistance of particle shells. The evident roughness of microparticles from Run 5 may explain the FPF that was about $70 \%$. Surface roughness decreases the contact area between adjacent microparticles, thus reducing the inter-particulate cohesive forces [31]. This observation is in agreement with Chew et al. who demonstrated how the increase in surface roughness of spray-dried bovine serum albumin particles can result in enhancement of the aerodynamic performance, in terms of fine particle fraction [32]. However, the size of the nanoparticles released in water from Run 5 powder remained high.

\section{Conclusions}

In this work, we have studied the preparation by spray drying of inhalable mannitol microparticles embedding nanoparticles of calcium phosphate. The ratio of mannitol: 
nanoparticle content is the parameter that increases the respirability of the powder but, more significantly, protects the size of the released nanoparticles upon mannitol dissolution. The feed rate parameter, which is considered relevant for the yield of an industrial manufacturing process, was less significant for the characteristics of the microparticles obtained. However, in certain manufacturing conditions, the interaction of this process-related factor with the nanoparticle concentration was observed to be beneficial for microparticle respirability.

The plots of Figure 11A,B quantify the effect of nanoparticle and carrier contents and their ratio on the released nanoparticles size and fine particle dose of microparticles. Increasing the mannitol concentration vs. the CaPs amount, increased the microparticle respirability and, more evidently, preserved the size of released nanoparticles. These quality attributes are crucial for the use of microparticles embedding nanoparticles for targeting the lung first and then the heart.

A

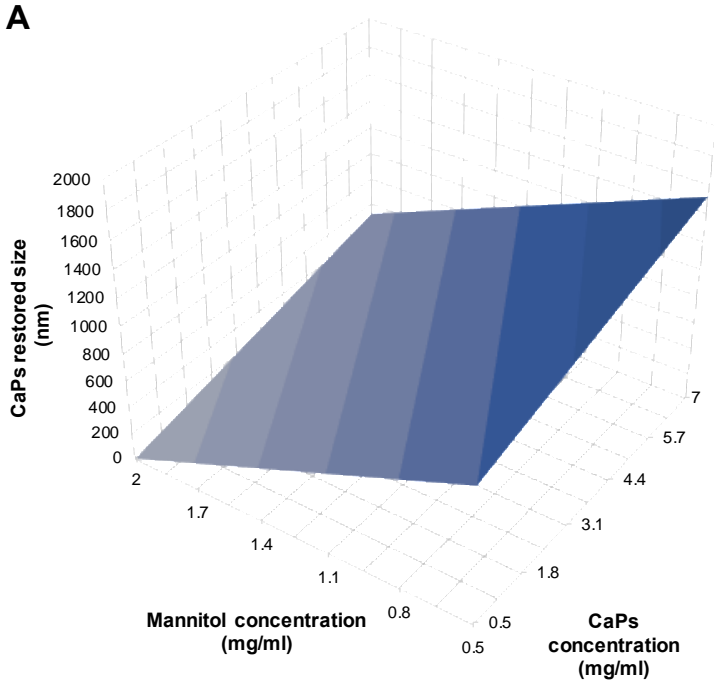

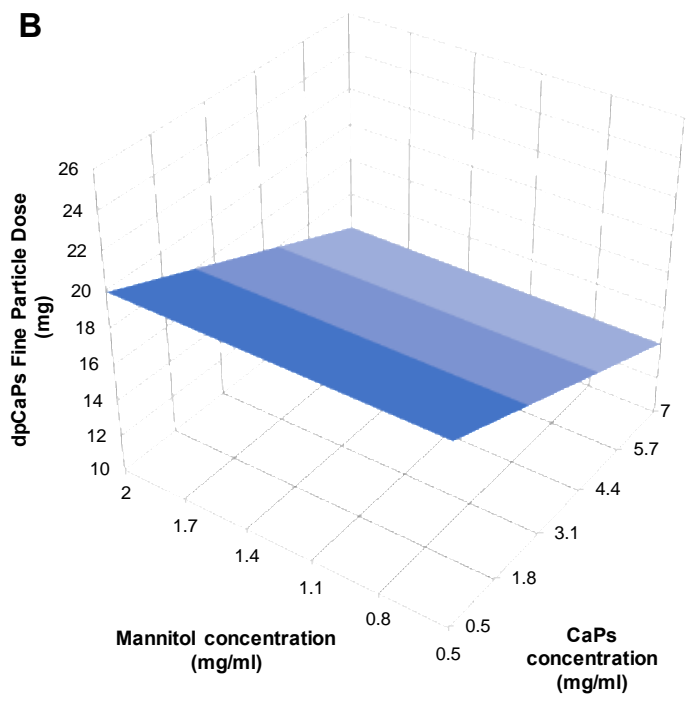

Figure 11. 3D graphs of nanoparticle/mannitol concentration and restored nanoparticles size (A) or Fine Particle Dose of microparticles (B) at fixed spray drying feed rate of $5.25 \mathrm{~mL} / \mathrm{min}$.

Taking up the observations relating to the morphology of microparticles embedding $\mathrm{CaP}$ nanoparticles, the concentration of the nanoparticles in the droplet subjected to drying led to microparticle structures that changed from spherical to dimpled and eventually to doughnut. This depends on the ratio between CaPs and mannitol as well. The respirability of these structures do not change too much, but the size of nanoparticles released upon dissolution of the carrier largely increases as the mannitol content is reduced. In this composite system for nanoparticle release in the lung, mannitol acts as a carrier capable of regulating the respirability but, more importantly, protecting the size of the released nanoparticles.

Finally, it is worth noticing that this work started from a pilot batch of nanoparticles done in an industrial environment. Spray drying at the industrial level has been already carried out with positive results.

\section{Patents}

Part of this research work is included in the Patent Application N ${ }^{\circ} 102020000021292-$ 2020; Catalucci D, Iafisco M, Colombo P, Quarta E.

Supplementary Materials: The following are available online at https:/ /www.mdpi.com/article/10 .3390/pharmaceutics13111825/s1; Table S1. Polydispersity index (PdI) and ל-Potential of dispersed CaPs after powder dissolution in water. 
Author Contributions: Conceptualization, P.C., E.Q., F.S., R.B. and F.B.; investigation, E.Q., L.D.E., G.T. and A.D.; data analysis and interpretation, A.R., D.M.R., M.I., C.D.L., E.Q. and T.W.W.; data curation, E.Q., F.B., P.C. and R.B.; writing-original draft preparation, E.Q., P.C., G.C. and F.B.; writingreview and editing A.R., G.C., M.I., C.D.L., T.W.W.; supervision, P.C., M.I., C.D.L. and D.C.; funding acquisition, D.C. All authors have read and agreed to the published version of the manuscript.

Funding: This research was funded by the European Union's Horizon 2020 research and innovation program under project CUPIDO, grant agreement [No 720834].

Institutional Review Board Statement: Not applicable.

Informed Consent Statement: Not applicable.

Data Availability Statement: Not applicable.

Acknowledgments: The authors would like to thank RPC Plastiape Spa (Osnago, Italy) and Qualicaps ${ }^{\circledR}$ Europe, S.A.U. (Spain) for kindly supplying the RS01 ${ }^{\circledR}$ inhaler and HPMC capsules, respectively. The authors dedicate this paper to Carla Caramella, University of Pavia, Italy, on the occasion of her Emeritus Professor recognition.

Conflicts of Interest: The authors declare no conflict of interest. E.Q., P.C. affiliated with PlumeStars srl., R.B. and F.B. are founders and stakeholders of PlumeStars SRL. The company had no role in the design of the study; in the collection, analyses, or interpretation of data; in the writing of the manuscript, and in the decision to publish the results.

\section{References}

1. Rusconi, F.; Ceriotti, P.; Miragoli, M.; Carullo, P.; Salvarani, N.; Rocchetti, M.; Pasquale, E.D.; Rossi, S.; Tessari, M.; Caprari, S.; et al. Peptidomimetic Targeting of Cav $\beta 2$ Overcomes Dysregulation of the L-Type Calcium Channel Density and Recovers Cardiac Function. Circulation 2016, 134, 534-546. [CrossRef] [PubMed]

2. Miragoli, M.; Ceriotti, P.; Iafisco, M.; Vacchiano, M.; Salvarani, N.; Alogna, A.; Carullo, P.; Ramirez-Rodríguez, G.B.; Patrício, T.; Esposti, L.D.; et al. Inhalation of Peptide-Loaded Nanoparticles Improves Heart Failure. Sci. Transl. Med. 2018, 10, eaan6205. [CrossRef] [PubMed]

3. Malamatari, M.; Charisi, A.; Malamataris, S.; Kachrimanis, K.; Nikolakakis, I. Spray Drying for the Preparation of NanoparticleBased Drug Formulations as Dry Powders for Inhalation. Process 2020, 8, 788. [CrossRef]

4. Politis, S.N.; Colombo, P.; Colombo, G.; Rekkas, D.M. Design of Experiments (DoE) in Pharmaceutical Development. Drug Dev. Ind. Pharm. 2017, 43, 889-901. [CrossRef]

5. Buttini, F.; Rozou, S.; Rossi, A.; Zoumpliou, V.; Rekkas, D.M. The Application of Quality by Design Framework in the Pharmaceutical Development of Dry Powder Inhalers. Eur. J. Pharm. Sci. 2018, 113, 64-76. [CrossRef]

6. Esposti, L.D.; Dotti, A.; Adamiano, A.; Fabbi, C.; Quarta, E.; Colombo, P.; Catalucci, D.; Luca, C.D.; Iafisco, M. Calcium Phosphate Nanoparticle Precipitation by a Continuous Flow Process: A Design of an Experiment Approach. Crystals 2020, 10, 953. [CrossRef]

7. Iafisco, M.; Bosco, R.; Leeuwenburgh, S.C.G.; van den Beucken, J.J.J.P.; Jansen, J.A.; Prat, M.; Roveri, N. Electrostatic Spray Deposition of Biomimetic Nanocrystalline Apatite Coatings onto Titanium. Adv. Eng. Mater. 2012, 14, B13-B20. [CrossRef]

8. Dormenval, C.; Lokras, A.; Cano-Garcia, G.; Wadhwa, A.; Thanki, K.; Rose, F.; Thakur, A.; Franzyk, H.; Foged, C. Identification of Factors of Importance for Spray Drying of Small Interfering RNA-Loaded Lipidoid-Polymer Hybrid Nanoparticles for Inhalation. Pharmaceut. Res. 2019, 36, 142. [CrossRef]

9. Kanojia, G.; Willems, G.-J.; Frijlink, H.W.; Kersten, G.F.A.; Soema, P.C.; Amorij, J.-P. A Design of Experiment Approach to Predict Product and Process Parameters for a Spray Dried Influenza Vaccine. Int. J. Pharmaceut. 2016, 511, 1098-1111. [CrossRef] [PubMed]

10. LeClair, D.A.; Cranston, E.D.; Xing, Z.; Thompson, M.R. Optimization of Spray Drying Conditions for Yield, Particle Size and Biological Activity of Thermally Stable Viral Vectors. Pharmaceut. Res. 2016, 33, 2763-2776. [CrossRef]

11. Maa, Y.-F.; Nguyen, P.-A.; Andya, J.D.; Dasovich, N.; Sweeney, T.D.; Shire, S.J.; Hsu, C.C. Effect of Spray Drying and Subsequent Processing Conditions on Residual Moisture Content and Physical/Biochemical Stability of Protein Inhalation Powders. Pharmaceut. Res. 1998, 15, 768-775. [CrossRef]

12. Belotti, S.; Rossi, A.; Colombo, P.; Bettini, R.; Rekkas, D.; Politis, S.; Colombo, G.; Balducci, A.G.; Buttini, F. Spray Dried Amikacin Powder for Inhalation in Cystic Fibrosis Patients: A Quality by Design Approach for Product Construction. Int. J. Pharmaceut. 2014, 471, 507-515. [CrossRef]

13. Vehring, R. Pharmaceutical Particle Engineering via Spray Drying. Pharmaceut. Res. 2008, 25, 999-1022. [CrossRef] [PubMed]

14. De Boer, A.H.; Thalberg, K. Inhaled Medicines; Chapter 5-Dry powder inhalers (DPIs); Academic Press: New York, NY, USA, 2021; pp. 99-146. [CrossRef]

15. Lechanteur, A.; Evrard, B. Influence of Composition and Spray-Drying Process Parameters on Carrier-Free DPI Properties and Behaviors in the Lung: A Review. Pharmaceutics 2020, 12, 55. [CrossRef] 
16. De Boer, A.H.; Hagedoorn, P.; Hoppentocht, M.; Buttini, F.; Grasmeijer, F.; Frijlink, H.W. Dry Powder Inhalation: Past, Present and Future. Expert. Opin. Drug Del. 2016, 14, 499-512. [CrossRef]

17. Thorley, A.J.; Ruenraroengsak, P.; Potter, T.E.; Tetley, T.D. Critical Determinants of Uptake and Translocation of Nanoparticles by the Human Pulmonary Alveolar Epithelium. ACS Nano 2014, 8, 11778-11789. [CrossRef] [PubMed]

18. Islam, M.A.; Barua, S.; Barua, D. A Multiscale Modeling Study of Particle Size Effects on the Tissue Penetration Efficacy of Drug-Delivery Nanoparticles. BMC Syst. Biol. 2017, 11, 113. [CrossRef]

19. Keil, T.W.M.; Feldmann, D.P.; Costabile, G.; Zhong, Q.; da Rocha, S.; Merkel, O.M. Characterization of Spray Dried Powders with Nucleic Acid-Containing PEI Nanoparticles. Eur. J. Pharm. Biopharm. 2019, 143, 61-69. [CrossRef] [PubMed]

20. Peng, T.; Zhang, X.; Huang, Y.; Zhao, Z.; Liao, Q.; Xu, J.; Huang, Z.; Zhang, J.; Wu, C.; Pan, X.; et al. Nanoporous Mannitol Carrier Prepared by Non-Organic Solvent Spray Drying Technique to Enhance the Aerosolization Performance for Dry Powder Inhalation. Sci. Rep. 2017, 7, 46517. [CrossRef]

21. Torge, A.; Grützmacher, P.; Mücklich, F.; Schneider, M. The Influence of Mannitol on Morphology and Disintegration of Spray-Dried Nano-Embedded Microparticles. Eur. J. Pharm. Sci. 2017, 104, 171-179. [CrossRef]

22. Chougule, M.; Padhi, B.; Jinturkar, K.; Misra, A. Development of Dry Powder Inhalers. Recent Patents Drug Deliv. Formul. 2007, 1, 11-21. [CrossRef] [PubMed]

23. Littringer, E.M.; Mescher, A.; Schroettner, H.; Achelis, L.; Walzel, P.; Urbanetz, N.A. Spray Dried Mannitol Carrier Particles with Tailored Surface Properties-The Influence of Carrier Surface Roughness and Shape. Eur. J. Pharm. Biopharm. 2012, 82, 194-204. [CrossRef] [PubMed]

24. Boel, E.; Koekoekx, R.; Dedroog, S.; Babkin, I.; Vetrano, M.R.; Clasen, C.; den Mooter, G.V. Unraveling Particle Formation: From Single Droplet Drying to Spray Drying and Electrospraying. Pharmaceutics 2020, 12, 625. [CrossRef]

25. Singh, A.; Mooter, G.V. den Spray Drying Formulation of Amorphous Solid Dispersions. Adv. Drug Deliv. Rev. 2016, 100, 27-50. [CrossRef] [PubMed]

26. Vehring, R.; Snyder, H.; Lechuga-Ballesteros, D. Drying Technologies for Biotechnology and Pharmaceutical Applications; Chapter 7-Spray drying; Wiley Online Library: Hoboken, NJ, USA, 2020; pp. 179-216. [CrossRef]

27. Muddana, H.S.; Morgan, T.T.; Adair, J.H.; Butler, P.J. Photophysics of Cy3-Encapsulated Calcium Phosphate Nanoparticles. Nano Lett. 2009, 9, 1559-1566. [CrossRef] [PubMed]

28. Höistad, M.; Chen, K.C.; Nicholson, C.; Fuxe, K.; Kehr, J. Quantitative Dual-probe Microdialysis: Evaluation of [3H]Mannitol Diffusion in Agar and Rat Striatum. J. Neurochem. 2002, 81, 80-93. [CrossRef]

29. Gomez, M.; McCollum, J.; Wang, H.; Ordoubadi, M.; Jar, C.; Carrigy, N.B.; Barona, D.; Tetreau, I.; Archer, M.; Gerhardt, A.; et al. Development of a Formulation Platform for a Spray-Dried, Inhalable Tuberculosis Vaccine Candidate. Int. J. Pharmaceut. 2020, 593, 120121. [CrossRef] [PubMed]

30. Tsapis, N.; Dufresne, E.R.; Sinha, S.S.; Riera, C.S.; Hutchinson, J.W.; Mahadevan, L.; Weitz, D.A. Onset of Buckling in Drying Droplets of Colloidal Suspensions. Phys. Rev. Lett. 2005, 94, 018302. [CrossRef]

31. Wang, H.; Nobes, D.S.; Vehring, R. Particle Surface Roughness Improves Colloidal Stability of Pressurized Pharmaceutical Suspensions. Pharmaceut. Res. 2019, 36, 43. [CrossRef]

32. Chew, N.Y.K.; Tang, P.; Chan, H.-K.; Raper, J.A. How Much Particle Surface Corrugation Is Sufficient to Improve Aerosol Performance of Powders? Pharmaceut. Res. 2005, 22, 148-152. [CrossRef] 